$1,2,3$, and 4 years follow-up. Over this period were managed according to clinical need and NCG guidelines. $\mathrm{N}=124$. Targeted therapy defined as Prostacyclin, endothelin receptor antagonists, and phosphodiesterase 5 inhibitors.

Results Changes at 1st and 2nd time points (median 3 months and 1 year) show statistically significant improvements in patient reported outcomes and objective measures. The NTproBNP improvement peaks at 3 years and begins to tail off at 4 years. The 6MWD improvement plateaus out between 2 and 3 years. The CAMPHOR symptom score shows significant improvement including year 3. The 4-year 6MWD does not achieve statistical significance compared to baseline. Further investigation revealed that between the third and fourth year 22 subject's follow-up was not performed; 3 died, 1 transferred to another centre, 18 are awaiting their 4-year follow-up.

Conclusion Objective and patient reported measures of change over time show improvements for CTEPH patients up to 3 years. After 3 years it becomes more difficult to determine a categorical change. More $6 \mathrm{MW}$ and CAMPHOR data for the 4 year time point is needed to determine if initial improvements are sustained after 3 years in this patient group, or if the improvement seen really has begun to tail off as the results here may suggest. The 4-year follow-up data for the remaining 18 patients will be available later this year.

\section{S22 IMPROVED SYMPTOMS AND QUALITY OF LIFE AFTER PULMONARY ENDARTERECTOMY (PEA) IN PATIENTS WITH CHRONIC THROMBOEMBOLIC DISEASE (CTED) AND BORDERLINE PULMONARY HYPERTENSION (PH)}

doi:10.1136/thoraxjnl-2011-201054b.22

D Taboada, C Treacey, D Jenkins, J Pepke Zaba, K Sheares. Papworth Hospital NHS trust, Cambridge, UK

Background Chronic thromboembolic pulmonary hypertension (CTEPH) is defined by a mean pulmonary artery pressure (mPAP) $=25 \mathrm{~mm} \mathrm{Hg}$ at right heart catheterisation in patients with multiple chronic/organised occlusive thrombi in the pulmonary arteries. PEA is potentially curable and is the treatment of choice for patients with CTEPH. There is a small group of patients with CTED and exertional dyspnoea but with a resting MPAP that does not fulfil criteria for PH in whom PEA may be considered. The outcome of PEA in these patients has not been previously assessed.

Objective To assess the post PEA functional and haemodynamic outcomes in patients with symptomatic CTED and borderline PH. Methods Retrospective data were collected on patients with baseline mPAP of $=25 \mathrm{~mm} \mathrm{Hg}$ who underwent PEA at the UK and Ireland national referral centre between 2002 and 2010. Patients were reassessed 3 and 12 months after surgery. Right heart catheterisation was performed at baseline and 3 months post PEA.

\section{Abstract S22 Table 1}

\begin{tabular}{llll}
\hline & $\begin{array}{l}\text { Baseline } \\
(\mathbf{n}=\mathbf{1 6})\end{array}$ & $\begin{array}{l}\text { 3 months } \\
\text { post PEA } \\
(\mathbf{n}=\mathbf{1 6})\end{array}$ & $\begin{array}{l}\text { 12 months } \\
\text { post PEA } \\
(\mathbf{n}=\mathbf{1 1})\end{array}$ \\
\hline WHO class I/II/III/IV (\%) & $0 / 50 / 50 / 0$ & $50 / 50 / 0 / 0$ & $60 / 40 / 0 / 0$ \\
6MWT distance (m) & $403 \pm 113$ & $417 \pm 111$ & $438 \pm 88^{*}$ \\
6MWT min Sat02 (\%) & $88 \pm 7$ & $91 \pm 8^{*}$ & $93 \pm 4^{*}$ \\
mPAP (mm Hg) & $22 \pm 3$ & $16 \pm 3^{*}$ & \\
Cardiac Index (I/m/m $\left.{ }^{2}\right)$ & $2 \pm 0.5$ & $2.5 \pm 0.4$ & \\
PVR (dynes.s.cm-5) & $239 \pm 116$ & $126 \pm 33^{*}$ & \\
CAMPHOR symptoms & 10 & $2^{*}$ & $1^{*}$ \\
Activity & 6 & 3 & $0^{*}$ \\
Quality of life & 9 & $3^{*}$ & $1^{*}$ \\
\hline
\end{tabular}

${ }^{*} p<0.05$.
Results 558 patients underwent PEA at Papworth Hospital between 2002 and 2010. From those, 16 had symptomatic operable CTED and $\mathrm{mPAP}$ of $=25 \mathrm{~mm} \mathrm{Hg}$. Mean age was $45 \pm 17$ and $69 \%$ were female. All survived surgery and are currently alive at follow-up. The median length of stay was 13 days (IOR 6). Results are displayed in the Abstract S22 table 1 as mean \pm SD. WHO class data are expressed as percentages. CAMPHOR (Cambridge Pulmonary Hypertension Outcome Review) is a disease specific quality of life questionnaire and scores are expressed as median.

Conclusion In this small series of patients with CTED and borderline $\mathrm{PH}$, there was a significant symptomatic, haemodynamic and functional benefit from PEA at 1-year. Further research is required to assess the prognostic benefit in this population. We would like to acknowledge the national pulmonary hypertension centres in the UK and Ireland, and support by the Cambridge NIHR Comprehensive Biomedical Research Centre.

\section{S23 ACCURACY OF CONTRAST ENHANCED MR LUNG PERFUSION COMPARED TO PERFUSION SCINTIGRAPHY IN DIAGNOSING CHRONIC THROMBOEMBOLIC PULMONARY HYPERTENSION}

doi:10.1136/thoraxjnl-2011-201054b.23

${ }^{1} \mathrm{~S}$ Rajaram, ${ }^{1} \mathrm{~A} J$ Swift, ${ }^{1} \mathrm{D}$ Capener, ${ }^{2} \mathrm{C}$ Hill, ${ }^{2} \mathrm{C}$ Davies, ${ }^{3} \mathrm{R}$ Elliot, ${ }^{3} \mathrm{~J}$ Hurdman, ${ }^{3} \mathrm{R}$ Condliffe, ${ }^{1} \mathrm{~J} \mathrm{M}$ Wild, ${ }^{3} \mathrm{D}$ G Kiely. ${ }^{1}$ Academic Unit of Radiology, University of Sheffield, Sheffield, UK; ${ }^{2}$ Department of Radiology, Royal Hallamshire Hospital, Sheffield, UK; ${ }^{3}$ Pulmonary Vascular Disease Unit, Sheffield, UK

Purpose The purpose of our study was to assess the diagnostic accuracy and reliability of contrast enhanced MR lung perfusion compared to perfusion scintigraphy in patients with CTEPH.

Methods and Materials Retrospective analysis of patients investigated for CTEPH who had MR lung perfusion, perfusion scintigraphy and CTPA performed within a time interval of 5 days. The $M R$ images were acquired using a time resolved $3 \mathrm{D}$ spoiled gradient echo sequence. The sequence parameters: TE $1.1 \mathrm{~ms}$, TR $2.5 \mathrm{~ms}$, flip angle of $30^{\circ}, \mathrm{FOV}=48 \mathrm{~cm}^{2}$, slice thickness of $5 \mathrm{~mm}$, average of 32 slices and frame rate was 2 acquisitions per second. This was a breathhold sequence obtained after $0.05 \mathrm{ml} / \mathrm{kg}$ of Gadovist injection at $5 \mathrm{ml} / \mathrm{s}$ followed by a $20 \mathrm{ml}$ saline flush. The subtraction images and positive enhancement dataset were analysed in the coronal plane. Four static views perfusion scintigraphy views were obtained. Final diagnosis of CTEPH or non-CTEPH was made at a multidisciplinary meeting following detailed multi-modality assessment. Results 27 patients had a diagnosis of CTEPH and 55 patients were diagnosed as non-CTEPH. In the CTEPH group, MRI lung perfusion diagnosed 26 patients as CTEPH and 1 patient with distal surgically inaccessible disease as non-CTEPH. In the non-CTEPH group, four patients were diagnosed as CTEPH and 48 patients were identified

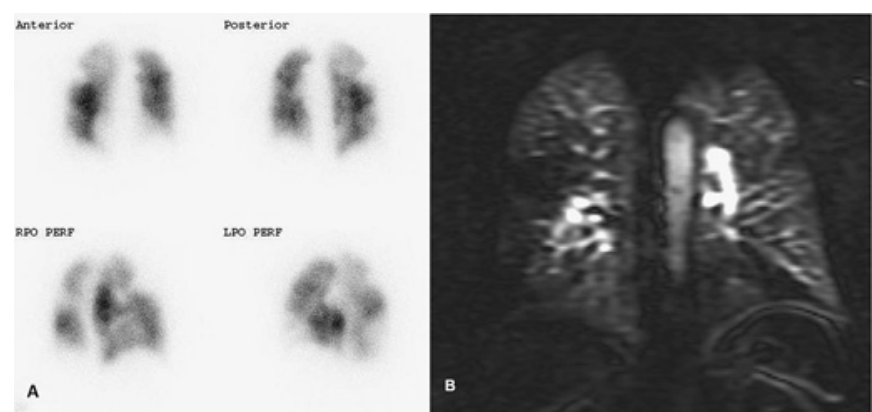

Abstract S23 Figure 1 